\title{
A Qualitative Study of Manager Experiences Using the RAFAELA System
}

\author{
Nina Berger Hustad ${ }^{*}$, Ragnhild Helles $\varnothing^{2}$, Marit Helen Andersen ${ }^{1,2}$ \\ ${ }^{1}$ Division of Cancer Medicine, Surgery and Transplantation, Oslo University Hospital, Norway \\ ${ }^{2}$ Faculty of Medicine, Institute of Health and Society, University of Oslo, Norway \\ Email: "nberger@ous-hf.no,ragnhild.helleso@medisin.uio.no,manderse@ous-hf.no
}

Received 29 September 2015; accepted 20 November 2015; published 23 November 2015

Copyright (C) 2015 by authors and Scientific Research Publishing Inc.

This work is licensed under the Creative Commons Attribution International License (CC BY). http://creativecommons.org/licenses/by/4.0/

c) (i) Open Access

\begin{abstract}
Objective: The objective was to explore manager experiences using the RAFAELA system. Background: The RAFAELA system was developed in Finland during the 1990s to create a work situation where patients' care needs were balanced with personnel resources. The system is used in almost all hospitals in Finland and is implemented in several European countries. However, the system has never been evaluated outside Finland. This study, focusing on the managers' perspective, represents the second report from a larger Norwegian evaluation project of the RAFAELA system. Methods: An explorative qualitative design was chosen. Data were collected by individual in-depth interviews at a university hospital in Norway during 2012-2013. A total of 10 informants in various management positions were interviewed. The tape-recorded interviews were transcribed verbatim, and the transcripts were analysed using Kvale's method for content analysis. Results: Four main themes emerged from the qualitative data: making the invisible visible; a common language; a system for prospective planning; and a resource-demanding tool. Conclusions: The study indicated that the RAFAELA system provided useful information about the patients' care needs and nursing activities. Also the system provided a common reference frame for discussing nursing, staffing and allocation. Although the managers considered the RAFAELA to be time consuming in the implementation phase, they considered the system to be an important tool.
\end{abstract}

\section{Keywords}

the RAFAELA System, Patients' Care Needs, Nurse Staffing, Manager Experiences, In-Depth Interviews

\section{Introduction}

In an era of changes in health care settings and the need for quality care, documenting of health care delivery is "Corresponding author. 
essential for nursing care and for the managers. Advancements in medicine lead to increasingly complex patient needs and nursing tasks [1]-[3]. Research has shown that nurses' contribution to the care and treatment of patients has a positive impact on patient outcomes and that successful staffing positively affects the quality of patient care. Health personnel represents one of the largest expenses in hospitals, and a better hospital staff is associated with lower hospital costs over time [2] [4]-[7].

Instruments that provide readily available information about patient care quality, regarding the processes and outcomes of the delivery system, are essential aspects of the effective health care. Regular feedback between nurses and managers provides useful information and impacts patient safety and quality of care [3] [8]. In an integrative review study, the researchers attempted to identify the current practice of using patient classification systems [9]. The results confirmed that there was no "gold standard" for measuring the nursing workload. Hence, there is a need for additional measurement and valid systems that capture the complexity of these factors. Other studies also revealed the lack of valid systems that analysed patients' care needs, patient flow and the use of available resources in medical and surgical hospital wards.

A better understanding of patient classification systems is expected to make hospitals more prepared for monitoring the developments pertaining to analysing patients' care needs and determining how to use the available resources [4] [10]. According to the Norwegian Parliament's Coordination Reform of 2009, lack of appropriate systems for resource allocation may be one of the reasons why proper patient care is insufficient [11]. In 2011 a Norwegian regional project called "Better Resource Management" was established, demonstrating the need to improve the opportunities for managers to engage in purposeful resource planning [12]. This was also the background for performing a broad evaluation of the Finnish RAFAELA system at Oslo University Hospital. The RAFAELA system was designed during the 1990s to create a work situation in which patients' care needs were balanced with personnel resources [13]-[15].

The Norwegian evaluation project included 4 sub studies [16]. The objective of this paper, representing the second report from the project, was to explore manager experiences using the RAFAELA system.

\section{Background}

The RAFAELA system, based on thorough research and user experiences in hospital contexts, is currently being used by more than 90\% of Finnish hospitals. Since 2010, Iceland, Norway, Sweden and the Netherlands also have become RAFAELA users [17].

The system is based on a three-part data collection system: i) daily patient classification as measured by the Oulu Patient Classification instrument (OPCq); ii) daily registration of nursing resources for direct care (N); and iii) professional assessment of optimal nursing care intensity level (PAONCIL). The workload is expressed in OPCq/N and is compared to the units' optimal standard for nursing intensity (NI) level defined by the nurses [13]-[15]. Hence, subjective perceptions are replaced by objective numbers. The OPCq instrument measures six sub-areas of patient needs and associated nursing interventions: 1) planning and coordination of care; 2) breathing, blood circulation and symptoms of disease; 3) nutrition and medication; 4) personal hygiene and excretion; 5) activity/movement, sleep and rest; and 6) teaching, guidance and follow-up in care, and emotional support. The nurses classify the patients once per day for the last 24-hour period. NI may vary for each sub-area between 1 - 4 points and are summed to a total score, ranging from 6 to 24 points per patient where 6 points indicate a patient with minimum needs and 24 points indicate a patient with intensive care needs. Total NI points at the unit were divided by the number of nurses, and the patient-related workload was obtained [13]-[15].

The assessment of optimal NI level per nurse is established by conducting a 4 - 6 weeks test using the PAONCIL instrument. On a scale from -3 to 3 , where -3 indicate very low and +3 very high NI, the nurses assess to which extent they have had the possibility to meet the needs of their patient group during the shift. The idea of the RAFAELA system is that the daily NI is compared to the optimal NI level for the ward. When the actual NI is on the optimal level, a successful resource allocation is obtained [14] [15] [18].

\section{Methods and Material}

\subsection{Design}

An explorative qualitative design was chosen, and individual semi-structured interviews were conducted. 


\subsection{Participants}

The participants were selected strategically to secure diversity and variation of the sample relevant to the aim of the study [19]-[20]. Eleven managers were asked to participate and a total of 10 informants (2 physicians and 8 nurses) agreed to participate. They represented all management levels of the division, being responsible for the treatment of patients, HR-planning, workload and budgeting. Background characteristics of the sample are demonstrated in Table 1.

\subsection{Data Collection Procedure}

The semi-structured interviews were performed in the period of September 2012 to April 2013. They lasted 40 60 minutes and took place in a suitable room with a relaxed atmosphere, starting with a briefing about the purpose of the study. One internal researcher and 1 external researcher attended the interviews to strengthen the scientific perspective and to ensure optimal ethical considerations. An interview guide consisting of open-ended questions was used to ensure that key aspects of the research question were covered. The guide was based on previous research within the field. It consisted of seven main questions covering the following areas: i) experiences with the daily use of the RAFAELA system, ii) the benefits and drawbacks of using the RAFAELA system, and iii) reflections and opinions about the future use of the RAFAELA system. At the end of the interviews, the participants were asked if there was anything they wished to add or comment on.

\subsection{Data Analysis}

The tape-recorded interviews where transcribed verbatim, and the transcripts were analysed using established methods for qualitative content analysis, containing five steps [21]. First, each interview was carefully read to obtain an overall impression of the data material. Then, the text was divided into meaning units, i.e., meaningful parts to capture the most probable interpretation of parts of the text. Third, the statements were read, and the themes that dominated a meaning unit were identified. The fourth step consisted of analysing the meaning units in terms of the specific purpose of the study: to describe the managers' experience with using the RAFAELA system. In the fifth step, the essential themes of the entire interview were tied together in a descriptive statement [21]. The method thus involved a condensation of the expressed meanings into more essential meanings of the structure and style to identify the manifestation of the informants' experiences. Examples from the data analysis process are shown in Table 2.

To assure the validity of the data, a pilot interview was conducted before the start of the study to evaluate the interview guide and the interview setting. To secure trustworthiness, the interview data were coded and reflected within the research group until the themes that were suited to the aim of the study were achieved [19]. Further analysis was performed by a pair of researchers who verified each other's work. Conformability was established

\begin{tabular}{llll}
\hline \multicolumn{2}{l}{ Table 1. Background characteristics of the informants. } & \\
\hline Informants & Managers & Number of nurses at the units & $\begin{array}{l}\text { Years of experiences } \\
\text { of mangers }\end{array}$ \\
\hline Informant nr. 1 & Unit manager & $>50$ & $<10$ \\
Informant nr. 2 & Unit manager & $=50$ & $<10$ \\
Informant nr. 3 & Division manager & $>50$ & $>10$ \\
Informant nr. 4 & Section manager & $>50$ & $>10$ \\
Informant nr. 5 & Section manager & $>50$ & $>10$ \\
Informant nr. 6 & Division manager & $>50$ & $>10$ \\
Informant nr. 7 & Unit manager & $<50$ & $>10$ \\
Informant nr. 8 & Division manager & $>50$ & $>10$ \\
Informant nr. 9 & Unit manager & $<50$ & $>10$ \\
Informant nr. 10 & Unit manager & $>50$ & $>10$ \\
\hline
\end{tabular}


Table 2. Examples from the data analysis process.

\begin{tabular}{|c|c|c|c|}
\hline Natural meaning units, statements & Meaning units & Sub themes & Theme \\
\hline $\begin{array}{l}\text { RAFAELA provides an increased } \\
\text { awareness of what you spend time on } \\
\text { during a day: those activities and all of the } \\
\text { tasks a nurse performs in caring for } \\
\text { patients. I do not think that you as a nurse } \\
\text { is aware of all the tasks performed } \\
\text { throughout the day. Hence, you are not } \\
\text { aware of the value of the tasks. } \\
\text { We think that we perform many } \\
\text { coordination tasks in our unit. The } \\
\text { RAFAELA reports support our } \\
\text { assumptions. We almost perform more } \\
\text { coordination tasks compared to direct } \\
\text { nursing. However, we wish to perform } \\
\text { more direct nursing work in the unit. }\end{array}$ & $\begin{array}{l}\text { RAFAELA provides increased awareness } \\
\text { of what the nurses are spending their time } \\
\text { on during the day and all the tasks they } \\
\text { complete. The system provides awareness } \\
\text { of the work and the value of nursing. }\end{array}$ & $\begin{array}{l}\text { RAFAELA creates awareness } \\
\text { within nursing. The system } \\
\text { visualizes nursing and brings } \\
\text { value to it. }\end{array}$ & $\begin{array}{l}\text { Making the } \\
\text { invisible visible }\end{array}$ \\
\hline
\end{tabular}

by maintaining an audit trail. Steps were taken to enhance the credibility, including using Kvale's [21] framework for the analysis, supervision by experienced researchers, keeping a research diary and using the participants own words when reporting the results.

\subsection{Ethical Considerations}

The study was conducted in accordance with the Helsinki declaration and was approved by the Internal Study Board at the Oslo University Hospital (\#2010/27572). Informed consent to participate was obtained from all the participants. In this study, the anonymity of the informants might be threatened because there were a few managers at each management level and thus the informants could be easily recognizable. Hence, we removed the recognizable statements to strengthen the anonymity and confidentiality of the data. The study was considered not to be a burden for the participants.

The RAFAELA system is owned by the Association of Finnish Local and Regional Authorities, and its use is managed by FCG_-Finnish Consulting Group Ltd. The actual study was initiated by the university hospital. The license to use the system was acquired through a standard agreement between the actual hospital and FCG.

\section{Results}

The participants ranged in age from 35 to 61 years. Four main themes emerged from the data analysis: Making the invisible visible; A common language; A system for prospective planning, and A resource demanding tool.

\section{Making the invisible visible}

According to the informants, the RAFAELA system visualized nursing in several different ways that helped to make the nurses more aware of what they actually were doing during a day, referring to the RAFAELA sub-areas: planning and coordination of care; breathing, blood circulation and symptoms of disease; nutrition and medication; personal hygiene and excretion; activity/movement, sleep and rest; and teaching, guidance and follow-up in care/emotional support. Additionally, it was stated that the system defined each patient's needs for nursing care activities and helped the nurses assess their own work more thoroughly. The RAFAELA reports assisted the leaders by highlighting key nursing areas in the unit and thus contributed to make the nursing activities more visible. Data also showed that using the system provided increased awareness regarding nursing tasks performed during their shifts, and helped the nurses appreciate the value of their work:

"The diffuse, but very important part of nursing care was made visible through the RAFAELA system."

"It is important that the nurses can be aware of what they actually do. How do we use the nursing resources, what are the patient care needs, and what to do to meet them?"

"The RAFAELA system increases the awareness of what nurses spend time on. I think that the nurses are not fully aware of all tasks performed during a day and that they do not reflect on the value of their work."

Also the informants experienced RAFAELA reports to be useful for illustrating the resources used in each nursing area: 
"I usually show the reports at monthly staff meetings. The nurses recognize the situations documented by the system, for instance, when it comes to those nursing areas that are the most challenging in our ward."

"The diffuse tasks being very important and very time consuming, these are made visible through the RAFAELA system.”

\section{A common language}

The participants expressed that the RAFAELA system represented a common reference frame within nursing and across units. The system created a common understanding by encouraging nurses to discuss nursing and patient needs using terms, assessments and scales that were available from the system. Using a common model for resource-planning also made it easier to discuss and benchmark staffing across the wards:

"The system encourages discussions and contributes to a common understanding of what nursing is."

Several participants also mentioned that RAFAELA system supported them by providing arguments concerning the budgeting of nursing care. In their opinion, objective RAFAELA data provided credibility in discussions with nursing care executives confirming the reality at the wards:

"I just arrived from a meeting with experts from the economic department. I was told we are using too many temporary nurses from agencies. The RAFAELA system is a very effective tool for providing data relevant for such debates."

"There is something about being able to use graphs. The economists prefer tables and figures instead of assumptions, and in this way the RAFAELA system is a very useful tool."

\section{A system for prospective planning}

Another major theme dealt with the ability of the system to create a work situation where patients' care needs balanced with available personnel resources. This was related to daily resource planning, but also to revealing patterns of patient needs versus staffing over months and years:

"The managers get patient flow data that is very useful for the allocation of nurses. For instance, RAFAELA data documented less need for nurses on the Monday day-shift."

One of the informants also found the RAFAELA system to be a tool for knowledge development within decision making:

"Having this type of data in resource-planning is very important strategically for the future. It enables us to perform many analyses by ourselves without a lot of external consultants.”

The informants expressed that system was useful for benchmarking and networking between different units, and enhanced the transparency in the organization:

“Then, examining the patients' composition according to their care needs and whether they should be in this unit or another unit... This is important information concerning the clinic's budget process, related to the assessment of how to allocate nursing resources."

Concerning need of skill mix within nursing, it was stated that the system contributed to illustrate the level of expertise needed in the units. However, the informants experienced that a weakness of the system was that the nurse competence variable not directly was registered by the system.

\section{A resource-demanding tool}

The informants stated that the implementation of the RAFAELA system required systematic education for a long period. They expressed the need of dedicated training personnel and the importance of being well prepared for the implementation process. The RAFAELA system was characterized as a complex system consisting of three different instruments entailing regular reliability and validity tests:

"Implementing RAFAELA was challenging, and we spent a lot of resources. Hence, it becomes important to experience the benefits and appreciate the value of it."

The mangers also expressed that one-to-one training for managers was needed to enable them to use the system in a comprehensive way. This included using the RAFAELA reports correctly, interpreting available information, and providing arguments for decision-makers in resource planning and allocating. In addition, it was stressed that it was important for managers to use the system actively and regularly.

\section{Discussion}

The findings of our study reflect two overall perspectives. The themes "Making the invisible visible" and "A common language” illustrate how RAFAELA contributed to awareness, and the visibility, of nursing care and thus provided the managers with an overall nursing perspective. The themes "A system for prospective planning” and “A resource-demanding tool” illustrate a management perspective. 
The nursing perspective

Data indicated that through RAFAELA classifications, the nursing care activities were clearly defined based on the patients' care needs. Several factors may explain these findings.

First, RAFAELA allows each nurse in the unit to perform a patient classification based on a professional estimation of the patients' unique care needs and based on daily nursing resources spent on each patient. Second, the RAFAELA system is based on optimal nursing intensity levels at each unit, defined by the nurses over a period of 4 - 6 weeks every other year [13] [14]. This level seemed to be an important tool for the mangers in debating the situation of the unit, for instance, for the last month or the last week. The nurse mangers appreciated that the system allowed the manager and the staff to reflect on an increase or decrease in the nursing intensity level with reference to the optimal standard of the unit. In this way, the staff could actively participate in the allocation discussion together with their manager.

Another significant finding was that the RAFAELA system made nursing visible in the units. This, to a large extent, refers to invisible tasks essential for health service delivery [22]. An Italian study demonstrated that nurses described invisible care as reflexivity, review of care actions, collaborating with colleagues, being 'competent', and being aware of their clinical skills [23]. These phenomena were also mentioned by the participants when reflecting nursing activities being visible through the RAFAELA system. Our findings have been confirmed by other studies [24] [25], revealing the complex nature of nursing performance. Through descriptions of nursing and the use of patient classification systems, the profession's contribution to the patient's health was made visible. Some of the participants mentioned that one advantage of using RAFAELA data was that the system provided a reliable picture of the activities nurses perform during a shift. The importance of displaying the different areas of nursing activities, such as teaching, guidance or administration of medication also was stressed by the participants. Most likely, this is useful information for the nurse managers for recruiting purposes, staff education, and also for providing a profile of their unit. Previous studies have verified the importance of mapping nurse competency and established relevant nursing skills to deliver high-quality patient care [26] [27].

In a report by Fasoli \& Haddock [9] the researchers argued that the lack of standardized language for communication and problems with describing what nurses do are obstacles for nursing workload measurement. However, one could present this argument in the opposite way. Using valid systems for workload measurement will contribute to common descriptions of what nurses do. Several studies have confirmed that measuring nursing care outcomes is important for nursing practice. Such information is crucial for increased quality within nursing [4] [24] [25].

In a review of conceptualization nursing workload, it was stated that the complexity of nursing makes it difficult to describe workload, and that there is no common definition of nursing workload in the literature [28]. Our findings indicated that the RAFAELA system contributed to a common language. The respondents in our study mentioned that the level of disagreement in the implementation process occurred when rating the six sub areas of the OPCq. The study of Andersen et al. supported this finding [16] and highlights the importance for nurses to be aware of their own work and participate in discussions about the nature of nursing. The participants stated that the system contributed to a professional understanding, not only for nurses, but also for the hospital managers because the same model and language were used in management discussions across units and clinics. In their report Brown et al stressed the importance of providing hospitals with common indicators describing nursing in addition to traditional medical outcomes [29]. This is in line with our findings demonstrating the managers' need of using feasible instruments providing professional understanding of patient needs and nursing workload.

\section{The management perspective}

According to the managers participating in the study the RAFAELA system was a useful tool for prospective planning. Among others the participants experienced the system to be an administrative tool for daily resource planning. Additionally, the system could support the managers in monitoring the sufficiency of available resources versus patient needs from day to day. A review study from 2011 supports our findings [30], revealing important factors that impact the nursing workload, such as nursing environment, nursing team, and the patient-nurse relationship. This finding is in line with the main idea of the RAFAELA system: to create a work situation in which patient care needs are balanced with personnel resources [13]-[15].

The participants experienced the RAFAELA system to be useful for revealing patient flow, allocation and benchmarking. Hence, in their opinion, the system was effective at addressing the increasing demands in the delivery of health care. In addition, they expressed that the reports could be used for discussions related to the 
quality of nursing care and how to meet individual care needs. The reports were also useful when debating staff planning at the level of administration managers and experts representing the finance department. In their review study Harper \& McCully demonstrated the importance for nurse managers using patient classification systems to ensure quality care and predict staffing needs [31].

Our findings indicate that valid patient classifications system must be established to provide a basis for staff planning, estimating costs, and providing nurses reasonable time and the possibilities to provide high-quality care. This is supported by Baernholdt et al. recommending building in-hospital structures of information systems as useful management tools [32].

Some negative aspects using the RAFAELA system was mentioned. The participants agreed that implementing RAFAELA was a time-consuming process. Additionally, the implementation process was considered to be quite a challenging and complex process. The findings are supported by previous research of implementing patient classification systems [9] [10] [26] [29]. From a management perspective, this is easy to understand. Implementing a new patient classification system requires education of the entire staff, thorough discussions within the nursing group, including decision making, and quality assurance during the process. Our study provided new, detailed insight into the process of implementing new tools into a busy hospital setting. The RAFAELA system is based on three types of data collection and according to the manual, the system has to be tested for reliability and validity before implementing it into a hospital unit [13]-[15]. These tests are time consuming and complex and therefore implementing the system is scheduled to take approximately 3 - 6 months per unit [14]. To solve the aspects concerning implementing the system we propose individual web-based introduction programs. Further, interactive web-based training programs for managers of using and interpreting RAFAELA reports would be purposeful. To evaluate web-based introduction-and training programs new evaluation studies should be conducted.

The informants also stated that system revealed nurse competence to a very little extent. This is a well know weakness of the system as nurses' competence and skill mix play an important role when balancing patients' care needs with personnel resources. According to the inventors integrating nurse competence is considered central in further development of the system [17]. If nurse competency will be included to a certain extent for the future, we propose new investigations to study how this important factor interacts with the RAFAELA system.

\section{Study Limitations}

Some study limitations should be mentioned. Our sample was based on data derived from only one hospital setting. Hence, caution should be used when transferring information from this study to other contexts. On the other hand, our study represents the first study of manager experiences of the RAFAELA system as used outside Finland. Thus, our study adds scientific information to the existing knowledge concerning the RAFAELA system.

Ten managers participated in the study. It is possible that more informants would provide multiple nuances and variations to the results. We addressed this by including maximum variation sampling in the range of experience, management level, age and gender.

\section{Conclusion}

The study indicated that the RAFAELA system provided useful information about the patients' care needs and nursing activities. Also the system provided a common reference frame for discussing nursing, staffing and allocation. Although the managers considered the RAFAELA system to be time consuming during implementation, they considered it to be an important tool.

\section{References}

[1] Adams, A. and Bond, S. (2003) Staffing in Acute Hospital Wards: Part 1. The Relationship between Number of Nurses and Ward Organizational Environment. Journal of Nursing Management, 11, 287-292. http://dx.doi.org/10.1046/j.1365-2834.2003.00361.x

[2] Lucero, R.J., Lake, E.T. and Aiken, L.H. (2009) Variations in Nursing Care Quality across Hospitals. Journal of Advanced Nursing, 65, 2299-2310. http://dx.doi.org/10.1111/j.1365-2648.2009.05090.x 
[3] McGillis Hall, L., Wodchis, W.P., Ma, X. and Johnson, S. (2013) Changes in Patient Health Outcomes from Admission to Discharge in Acute Care. Journal of Nursing Care Quality, 28, 8-16. http://dx.doi.org/10.1097/NCQ.0b013e3182665dab

[4] Kane, R.L., Shamliyan, T.A., Mueller, C., Duval, S. and Wilt, T.J. (2007) The Association of Registered Nurse Staffing Levels and Patient Outcomes: Systematic Review and Meta-Analysis. Medical Care, 45, 1195-1204. http://dx.doi.org/10.1097/MLR.0b013e3181468ca3

[5] Purcell, S.R., Kutash, M. and Cobb, S. (2011) The Relationship between Nurses' Stress and Nurse Staffing Factors in a Hospital Setting. Journal of Nursing Management, 19, 714-720. http://dx.doi.org/10.1111/j.1365-2834.2011.01262.x

[6] Aiken, L.H., Cimiotti, J.P., Sloane, D.M., Smith, H.L., Flynn, L. and Neff, D.F. (2011) Effect of Nurse Staffing and Nurse Education On Patients' Death in Hospital with Different Nurse Work Environments. Medical Care, 49, 1047-1053. http://dx.doi.org/10.1097/MLR.0b013e3182330b6e

[7] Aiken, L., Sloane, D.S., Bruyneel, L., Van den Heede, K., Griffiths, P., Busse, R., Diomidous, M., Kinnunen, J., Kózka, M., Lesaffre, E., McHugh, M.D., Moreno-Casbas, M.T., Rafferty, A.M., Schwendimann, R., Scott, A.P., Tishelman, C., Theo van Achterberg, T. and Sermeus, W. (2014) Nurse Staffing and Education and Hospital Morality in Nine European Countries: A Retrospective Observational Study. The Lancet, 383, 1824-1830. http://dx.doi.org/10.1016/S0140-6736(13)62631-8

[8] Pastastavrou, E., Andreou, P. and Efstathiou, G. (2014) Rationing of Nursing Care and Nurse-Patient Outcomes: A Systematic Review of Quantitative Studies. The International Journal of Health Planning and Management, 29, 3-25. http://dx.doi.org/10.1002/hpm.2160

[9] Fasoli, D.R. and Haddock, K.S. (2010) Results of an Integrative Review of Patient Classification Systems (Chap. 11). Annual Review of Nursing Research, 28, 295-316. http://dx.doi.org/10.1891/0739-6686.28.295

[10] Perroca, M.G. and Ek, A-C. (2007) Utilization of Patient Classification System in Swedish Hospitals and Degree of Satisfaction among Nursing Staff. Journal of Nursing Management, 15, 472-480. http://dx.doi.org/10.1111/j.1365-2834.2007.00732.x

[11] Report No. 47 to the Parliament 2009. The Coordination Reform 2008-2009.

[12] South-Eastern Norway Regional Health Authority (2012) Annual Report.

[13] Fagerström, L., Rainio, A.-K., Rauhala, A. and Nojonen, K. (2000) Validation of a New Method for Patient Classification, the Oulu Patient Classification. Journal of Advanced Nursing, 31, 481-490. http://dx.doi.org/10.1046/j.1365-2648.2000.01277.x

[14] Fagerström, L., Rainio, A.-K., Rauhala, A. and Nojonen, K. (2000) Professional Assessment of Optimal Nursing Care Intensity Level-A New Method for Resource Allocation as an Alternative to Classical Time Studies. Scandinavian Journal of Caring Sciences, 14, 97-104.

[15] Rauhala, A. and Fagerström, L. (2004) Determining Optimal Nursing Intensity: The RAFAELA Method. Journal of Advanced in Nursing, 45, 351-359. http://dx.doi.org/10.1046/j.1365-2648.2003.02918.x

[16] Andersen, M.H., Lønning, K. and Fagerström, L. (2014) Testing Reliability and Validity of the Oulu Patient Classification Instrument-The First Step in Evaluating the RAFAELA System in Norway. Open Journal of Nursing, 4, 303311. http://dx.doi.org/10.4236/ojn.2014.44035

[17] Fagerström, L., Lønning, K. and Andersen, M.H. (2014) The RAFAELA System: A Workforce Planning Tool for Nurse Staffing and Human Resource Management. Nursing Management, 21, 30-36. http://dx.doi.org/10.7748/nm2014.04.21.2.30.e1199

[18] Fagerström, L. and Rauhala, A. (2007) Benchmarking in Nursing Care by the RAFAELA Patient Classification System. Journal of Nursing Management, 15, 683-692. http://dx.doi.org/10.1111/j.1365-2934.2006.00728.x

[19] Polit, C.F. and Beck, C.T. (2004) Nursing Research: Principles and Methods. 7th Edition, Lippincott Williams \& Wilkins, Philadelphia.

[20] Patton, M.Q. (2002) Qualitative Research \& Evaluation Methods. 3rd Edition, SAGE Publications, Thousand Oaks.

[21] Kvale, S. (2007) Det kvalitative forskningsintervju. Gyldendal Norsk forlag AS.

[22] Allen, D. (2007) What Do Nurses Do at Work? Profession Building and Doing Nursing. International Council of Nurses, 54, 41-48. http://dx.doi.org/10.1111/j.1466-7657.2007.00496.x

[23] Canzan, F., Heilemann, M.V., Saiani, L., Mortari, L. and Ambrosi, E. (2014) Visible and Invisible Caring in Nursing from the Perspectives of Patients and Nurses in the Gerontological Context. Scandinavian Journal of Caring Sciences, 28, 732-740. http://dx.doi.org/10.1111/scs.12105

[24] Hendrich, A., Chow, M., Skierczynski, B.A. and Lu, Z. (2008) A 36-Hospital Time and Motion Study: How Do Medical-Surgical Nurses Spend Their Time? The Permanente Journal, 12, 25-34. http://dx.doi.org/10.7812/TPP/08-021 
[25] Cornell, P., Riordan, M., Townsend-Gervis, M. and Mobley, R. (2011) Barriers to Critical Thinking Workflow Interruptions and Task Switching among Nurses. The Journal of Nursing Administration, 41, 407-414. http://dx.doi.org/10.1097/NNA.0b013e31822edd42

[26] Harper, K. and McCully, C. (2007) Acuity System Dialog and Patient Classification System Essentials. Nursing Administration Quarterly, 31, 284-299. http://dx.doi.org/10.1097/01.NAQ.0000290426.41690.cb

[27] Whelchel, C., Berg, L., Brown, A., Hurd, D., Koepping, D. and Stroud, S. (2013) What's the Impact of Quality Bundles at the Bedside? Nursing, 43, 18-21. http://dx.doi.org/10.1097/01.NURSE.0000437481.30251.e1

[28] Morris, R., MacNeela, P., Scott, A., Treacy, P. and Hyde, A. (2007) Reconsidering the Conceptualization of Nursing Workload: Literature Review. Journal of Advance Nursing, 57, 463-471. http://dx.doi.org/10.1111/j.1365-2648.2006.04134.x

[29] Brown, D.S., Donaldson, N., Burnes Bolton, L. and Aydin, C.E. (2010) Nursing-Sensitive Benchmarks for Hospital to Gauge High-Reliability Performance. Journal of Health Quality, 32, 9-17. http://dx.doi.org/10.1111/j.1945-1474.2010.00083.x

[30] Myny, D., Van Gouberger, D., Gobert, M., Vanderwee, K., Van Hecke, A. and Defloor, T. (2011) Non-Direct Patient Care Factors Influencing Nursing Workload: A Review of the Literature. Journal of Advanced Nursing, 67, 21092129.

[31] Harper, K. and McCully, C. (2007) Acuity Systems Dialogue and Patient Classification System Essentials. Nursing Administration Quarterly, 31, 284-299. http://dx.doi.org/10.1097/01.NAQ.0000290426.41690.cb

[32] Baernholdt, M., Cox, K. and Scully, K. (2010) Using Clinical Data to Capture Nurse Workload. Implications for Staffing and Safety. CIN: Computers, Informatics, Nursing, 28, 229-234. 